\title{
EROSÃO HÍDRICA EM CAMBISSOLO HÚMICO ALUMÍNICO SUBMETIDO A DIFERENTES SISTEMAS DE PREPARO E CULTIVO DO SOLO: II. PERDAS DE NUTRIENTES E CARBONO ORGÂNICO(1)
}

\author{
J.SCHICK (2), I. BERTOL (3), \\ A. A. BALBINOT J ÚNIOR ${ }^{(4)} \&$ O. BATISTELA ${ }^{(4)}$
}

\begin{abstract}
RESUMO
A erosão hídrica é uma das principais causas do empobrecimento dos solos, por causa do transporte de nutrientes. Os nutrientes são transportados pela erosão hídrica adsorvidos aos colóides do solo e, ou, solubilizados, podendo variar com o sistema de preparo do solo. Este trabal ho foi desenvolvido no Campus do Centro de Ciências Agroveterinárias de Lages (SC), no período de janeiro de 1993 a outubro de 1998, com o objetivo de quantificar as perdas por erosão de fósforo, potássio, cálcio, magnésio e carbono orgânico sob chuva natural, nos seguintes sistemas de preparo: (a) aração + duas gradagens, (b) escarificação + gradagem e (c) semeadura dir eta executados no sentido paralelo ao declive, com rotação e sucessão de culturas nos três sistemas. Na rotação, foi utilizada a seguinte seqüência de culturas: soja, aveia preta, feijão, ervil haca comum, mi lho, ervilhaca comum, soja, trigo, feijão, nabo forrageiro, milho e aveia preta e, na sucessão, trigo e soja em todos os anos. Outro tratamento constou de (d) aração + duas gradagens + solo sem cultura, preparado no sentido paralelo ao declive. Utilizou-se um Cambissolo Húmico al umínico argiloso, com 0,102 $\mathrm{m} \mathrm{m}^{-1}$ de declividade média. A concentração de fósforo, potássio, cálcio, magnésio e carbono orgânico no solo foi, em geral, maior nos preparos conservacionistas do que nos convencionais. No entanto, a perda total dos referidos elementos foi, em geral, pouco influenciada pelos sistemas de preparo do solo, relacionando-se fracamente com as perdas de solo e água. As concentrações desses nutrientes no sedimento da erosão correlacionaram-se positivamente com as suas concentrações na camada de 0-0,025 m de profundidade do solo, apresentando uma taxa de enriquecimento próximo a um.
\end{abstract}

Termos de indexação: preparo conservacionista, semeadura direta, rotação de culturas, sucessão de culturas.

\footnotetext{
(1) Parte da Tese de M estrado do primeiro autor, apresentada à Faculdade de Agronomia do CAV/UDESC, Lages (SC), como um dos requisitos para conclusão do Curso de Mestrado em Ciência do Solo. Executado com recursos parciais da FI NEP/CAPES/UDESC. Recebido para publicação em agosto de 1999 e aprovado em fevereiro de 2000.

(2) Pós-Graduando em Agronomia do CAV/UDESC. Caixa Postal 281, CEP 88520-000 Lages (SC). Bolsista do CNPq.

(3) Professor do Centro de Ciências Agroveterinárias, UDESC. Bolsista do CNPq. E-mail a2ib@cav.udesc.br.

(4) Graduando do Curso de Agronomia do CAV/UDESC. Bolsista de I niciação Científica PIBIC.
} 


\title{
SUMMARY: SOIL EROSION OF A CLAYEY INCEPTISOL UNDER DIFFERENT CROP AND TILLAGE SYSTEMS:II. NUTRIENT AND ORGANIC CARBON LOSSES
}

\begin{abstract}
Erosion is oneof themain causes of soil degradation because of thetransport of nutrients. The nutrients are transported by water either dissolved or adsorbed on the soil particles, and the erosion rate may vary according to the tillage system. This work was conducted at the Centro de Ciências Agroveterinárias in Lages, Santa Catarina, Brazil, from J anuary 1993 to October 1998, to quantify the losses of phosphorus, potassium, calcium, magnesium and organic carbon due to erosion caused by natural rainfall in the following soil tillage systems: no-tillage, chisel pl ow plus disking, and pl owing plus disking. Both, crop rotation and succession, were used for thesethreesoil preparation systems. An additional treatment consisted of bare soil tillage + pl owing plus disking. Soybean, oat, bean, vetch, corn, vetch, soybean, wheat, bean, fodder radish, corn, and oat werecropped in rotation and wheat and soybean in crop succession. The soil was a clayey I nceptisol (Haplumbrept) with a slope of $0.102 \mathrm{~m} \mathrm{~m}^{-1}$. The soil concentration of phosphorus, potassium, calcium, magnesium and organic carbon was higher under conservation tillage than conventional tillage. Total loss of the el ements, however, was littl e influenced by thetillage systems, but were related with soil and water losses. The concentration of those elements in the erosion sediment was correl ated with their concentration in 0-0.025 $\mathrm{m}$ soil layer, with presenting an enrichment ratecloseto one
\end{abstract}

Index terms: conservation tillage, no-tillage, crop rotation, crop succession.

\section{NTRODUÇÃO}

A perda de nutrientes pela erosão hídrica é um dos principais fatores determinantes do empobrecimento dos solos e da redução da produtividade da maioria das culturas, com conseqüentes aumentos em seu custo de produção e na contaminação ambiental. Alguns trabalhos apontam perdas significativas de nutrientes por erosão hídrica, em relação ao que as culturas exigem (Bertol \& Miquelluti, 1993; Schwarz, 1997; Schick, 1999), refletindo-se no custo de produção das culturas. Além dos prejuízos econômicos, também deve ser considerada a deterioração da qualidade das águas superficiais, onde os elementos são depositados.

A perda de nutrientes pode ser expressa tanto em concentração do elemento na suspensão ou no sedimento, como em quantidade perdida por área. A concentração de determinado el emento na enxurrada varia principalmente com sua concentração no solo, queé influenciada pelas fertilizações, manejo etipo desolo. A quantidadetotal transportada, no entanto, depende tanto da concentração do el emento no material erodido quanto do volume total desse material perdido (Seganfredo et al., 1997).

Segundo Castro et al. (1986) e Dedecek et al. (1986), a variação no sistema de preparo do sol o não influencia a concentração de nutrientes no sedimento transportado, o que não foi confirmado por Seganfredo et al. (1997) e Schick (1999). Estudos relativos à efetividade de sistemas conservacionistas de preparo do solo no controle de perdas de nutrientes indicam que ototal de nutrientes perdidos por erosão hídrica decresce quando tais sistemas são utilizados (Burwell et al., 1975; Castro et al., 1986; Seganfredo et al., 1997; Schick, 1999). Isso seria atribuído aos efeitos combinados do aumento na cobertura do solo com restos culturais, decréscimo da incorporação defertilizantes ereduçãonas perdas de sol o e água (McDowell \& McGregor, 1984).

Seganfredo et al. (1997) afirmaram que o material erosi onado é mais rico em fósforo, cálcio, magnésio, potássio e matéria orgânica do que o solo original. Isto seria devidoà textura do material transportado, o qual é mais rico em silte e argila do que o solo de onde se originou o sedimento, uma vez que estas partículas são mais facilmente transportadas e contêm maiores quantidades de nutrientes adsorvidos (Freitas \& Castro, 1983).

Em geral, as perdas de carbono orgânico por erosão hídrica são el evadas (Schwarz, 1997; Schick, 1999) e podem constituir importante fator de degradação do solo. Em geral, sua concentração no sedimento erodido correlaciona-se linear e positivamente com a concentração na camada superficial do solo de onde o sedimento se originou, podendo essa perda ser facilmente prevista por regressão linear simples (Schwarz, 1997; Schick, 1999).

O objetivo destetrabal hofoi quantificar as perdas de fósforo, potássio, cálcio, magnésio e carbono orgânico no sedimento e na suspensão da erosão hídrica em diferentes sistemas de preparo e cultivo do solo. 


\section{MATE RIAL E MÉTODOS}

A local ização, período, área, desenho experimental, tratamentos e culturas deste experimento foram os mesmos descritos em Schick et al. (2000).

Em novembro de 1992, foi semeada a soja, adubada com $150+60 \mathrm{~kg}^{-1}$ de $\mathrm{P}_{2} \mathrm{O}_{5}+\mathrm{K}_{2} \mathrm{O}$, respectivamente, enquanto o trigo e a aveia preta, semeados em junho de 1993, receberam $200 \mathrm{~kg}$ ha-1 da fórmula 05-30-15 ea soja e o feijão, semeados em dezembro de 1993, $250 \mathrm{~kg}$ ha-1 da fórmula 5-20-10. O trigo e a ervilhaca comum, semeados em julho de 1994, foram adubados com $50+60 \mathrm{~kg} \mathrm{ha}-1$ de $\mathrm{P}_{2} \mathrm{O}_{5}+\mathrm{K}_{2} \mathrm{O}$ e $42+40 \mathrm{~kg} \mathrm{ha}^{-1}$ de $\mathrm{P}_{2} \mathrm{O}_{5}+\mathrm{K}_{2} \mathrm{O}$, respectivamente, enquanto a soja e o milho, semeados em dezembro de 1994, foram adubados, respectivamente, com $170+170 \mathrm{~kg} \mathrm{ha}-1$ e $140+150 \mathrm{~kg} \mathrm{ha-1}$ de superfosfato triplo + cloreto de potássio, respectivamente. O milho recebeu, ainda, $100 \mathrm{~kg}$ ha-1 de uréia em cobertura. Em agosto de 1995, foram semeados o trigo e a ervilhaca comum, ambos sem adubo formulado, tendo o trigo recebido $65 \mathrm{~kg} \mathrm{ha}-1$ de uréia em cobertura, enquanto a soja, semeada em dezembro de 1995, foi adubada com $250 \mathrm{~kg} \mathrm{ha}^{-1}$ da fórmula 8-18-30, e o trigo, semeado em maio de 1996, foi adubado com $170+170 \mathrm{~kg} \mathrm{ha}-1$ de superfosfato triplo + cloreto de potássio, respectivamente, além de $100 \mathrm{~kg} \mathrm{ha}^{-1}$ de uréia em cobertura. Em novembro de 1996, foi semeado o feijão, com 320 kg ha-1 da fórmula 5-25-25, e, em maio de 1997, foram semeados nabo forrageiro e trigo, adubados com $250 \mathrm{~kg} \mathrm{ha}^{-1}$ da fórmula 5-25-25, além de $100 \mathrm{~kg} \mathrm{ha}^{-1}$ de uréia em cobertura no trigo. 0 milho ea soja, semeados em novembro de 1997, foram adu bados com $300 \mathrm{~kg}$ ha-1 da fórmula 5-25-25, além de $100 \mathrm{~kg} \mathrm{ha}^{-1}$ de uréia em cobertura no milho, enquanto a aveia preta e o trigo, semeados em maio de 1998, foram adubados com $250 \mathrm{~kg}$ ha-1 da fórmula 5-20-10.

O procedimento para col eta e processamento das amostras de enxurrada seguiu o método sugerido por Cogo (1978). Em laboratório, as amostras contidas nos frascos de $300 \mathrm{ml}$ eram mantidas em repouso por 24 a 48 horas, com a finalidade de permitir a sedimentação do material em suspensão. Após esse período, o sobrenadante foi retirado por sifonamento. Os frascos com sedimento úmido foram, então, levados à estufa com circulação forçada dear, à temperatura de 55 à $60^{\circ} \mathrm{C}$, até atingirem massa constante. U ma alíquota de aproximadamente $10 \mathrm{ml}$ da suspensão sobrenadante foi coletada para posterior análisequímica dos nutrientes estudados.

O sedimento coletado após cada chuva erosiva individual, seco a 55 a $60^{\circ} \mathrm{C}$, contido nos frascos, foi retirado com auxílio de uma espátula earmazenado em potes plásticos, constituindo uma amostra única, média do período inteiro de cultivo. Uma alíquota de aproximadamente $10 \mathrm{ml}$, coletada em cada amostra de suspensão da enxurrada de chuvas individuais, foi agregada às demais e constituía uma amostra única, média do período inteiro de cultivo. Tais amostras eram armazenadas em geladeira, à temperatura de aproximadamente $4^{\circ} \mathrm{C}$. Ao final do cultivo, eram realizadas as análises químicas do sedimento seco e da suspensão armazenada em geladeira.

Nas amostras de sedimento de cada período de cultivo, foram determinadas, em três repetições, as concentrações de P extraível e K, Ca e Mg trocáveis ( $\mathrm{KCl} 1$ mol L-1) e, na suspensão, os teores de P, K, Ca e $\mathrm{Mg}$ solúveis. Os métodos de extração e determinação desses el ementos seguiram a descrição de Tedesco et al. (1995). No material coletado nos três últimos períodos de cultivo, determinou-se, ainda, o teor de carbono orgânico, através do método descrito em Tedesco et al. (1995).

Ao final do $10^{\circ}, 11^{\circ}$ e $12^{\circ}$ cultivos e antes da implantação das culturas subseqüentes, foram col etadas amostras de solo, na profundidade de 0 0,025 m, com três subamostras por amostra, em cada parcela, nas quais foram determinados os teores de P extraível, K, Ca e Mg trocáveis e carbono orgânico, conforme o método descrito em Tedesco et al. (1995). Informações mais detalhadas podem ser encontradas em Schick (1999).

\section{RESULTADOSE DISCUSSÃO}

Para discutir os dados, supôs-se que o sedimento removido das parcelas pela erosão era aquele da camada de 0-0,025 m de profundidade e comparouse a composi ção química do sedimento er odido com a do solo original na mesma profundidade.

Com base na média dos três últimos ciclos culturais estudados, o teor de fósforo na camada de 0-0,025 m na semeadura direta e escarificação + gradagem foi, respectivamente, 6,6 e2,6 vezes maior do que na aração + duas gradagens (Quadro 1), o que também foi verificado por Schwarz (1997) e Schick (1999). I sso pode ser atribuído, em parte, ao modo de aplicação dos fertilizantes na superfície do solo na semeadura direta e, respectivamente, semiincorporados e incorporados nos demais tratamentos, bem como à ausência de preparo na semeadura direta. Em relação ao sol o sem cultura, os teores de fósforo e potássio foram, respectivamente, 19,2 e 3,9 vezes maiores na semeadura direta, explicados pelas ausências de fertilização e culturas no tratamento aração + duas gradagens + solo sem cultura. Na mesma camada, o potássio, o cálcio e o magnésio apresentaram, em geral, teores semel hantes nos tratamentos estudados, provavelmente explicados pela maior mobilidade dos referidos nutrientes no solo, independentemente do sistema de manejo. 
Quadro 1. Teores médios de P extraível, K, Ca e Mg trocáveis do solo da camada de 0-0,025 m de profundidade e de carbono orgânico na mesma camada e no sedimento da erosão de um Cambissolo Húmico alumíni co submeti do a diferentes sistemas de preparo e sistema de cultivo (média da rotação e sucessão de culturas). Amostras dos ciclos culturais 10, 11 e 12

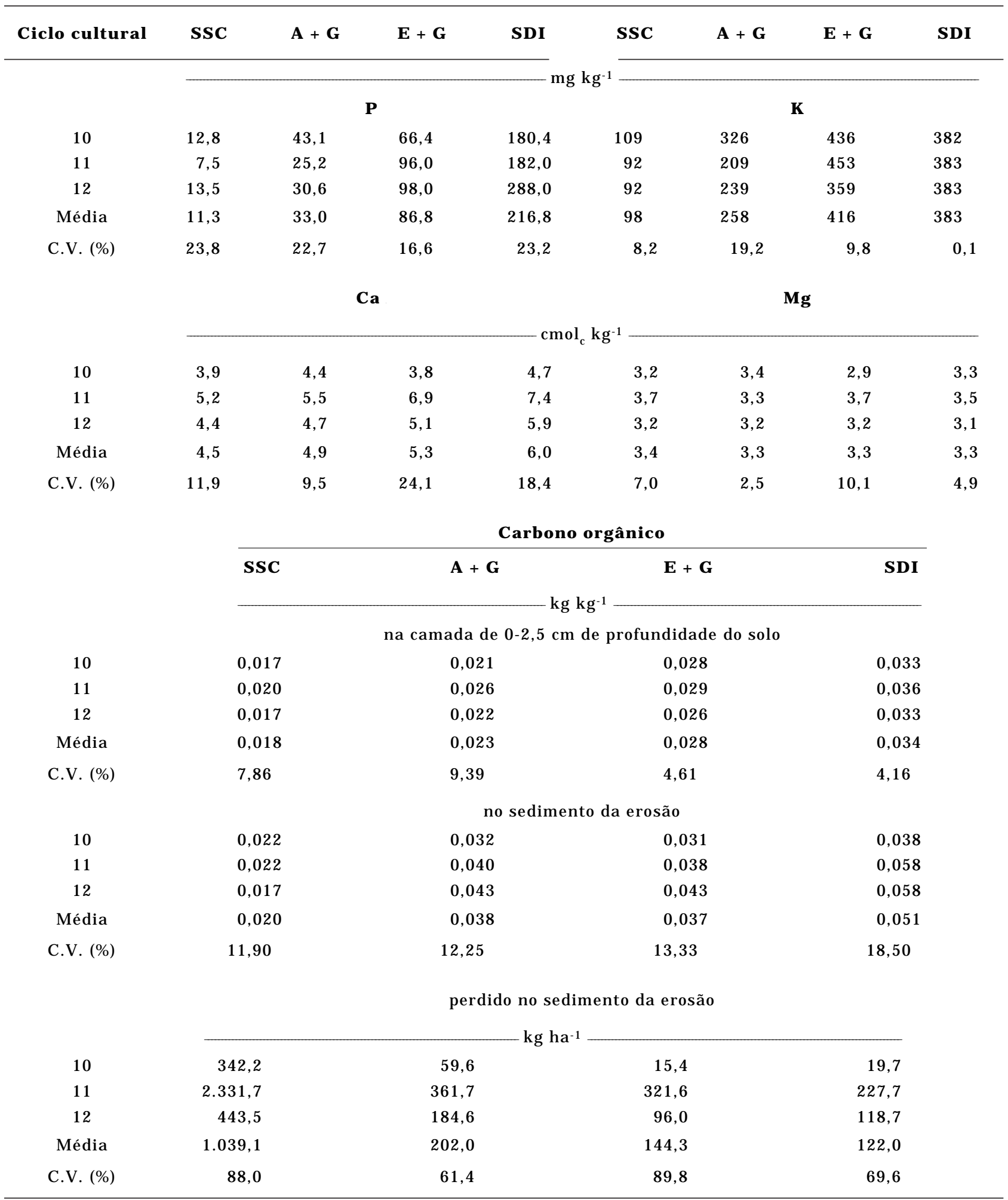

10: 01/05/97 a 15/11/97; 11: 16/11/97 a 30/04/98; 12: 01/05/98 a 30/10/98.

Sistemas de preparo do solo: SSC - solo sem cultura com aração + duas gradagens; A + G: aração + duas gradagens; E + G: escarificação + gradagem; SDI : semeadura direta; C.V.: coeficiente de variação. 
O carbono orgânico foi perdido em maor quantidade em todos os tratamentos (Quadro 1), concordando com Seganfredo et al. (1997), em razão de seu maior teor no solo e, ainda, porque a matéria orgânica é o primeiro constituinte a ser removido pela erosão, tendo em vista sua baixa densidade.

A proteção da superfície ocasionada pelos resíduos culturais e a ausência de preparo do solo na semeadura direta reduziram em cerca de 90 e $40 \%$ as perdas de carbono nesse tratamento em relação aos tratamentos aração + duas gradagens + solo sem cultura e aração + duas gradagens, respectivamente, na média dos três ciclos culturais estudados. I sto pode ser explicado, principalmente, pelas difer enças nas perdas desol o ocorridas nesses tratamentos (Schick et al., 2000) e, ainda, pelas variações na concentração de carbono no sedimento perdido por erosão (Quadro 1).
O teor dos nutrientes estudados no sedimento da erosão foi, em geral, maior nos sistemas de preparo conservacionistas, na média dos ciclos culturais estudados (Quadro 2), tendo sido alta no caso do fósforo e potássio. Assim, os teores de fósforo e potássio foram, respectivamente, cerca de 4,5 e 1,6 vezes maiores na semeadura direta do que na aração + gradagem, enquanto os de cálcio e os de magnésio foram 1,1 vez maiores. Os maiores teores de fósforo e potássio no sedimento da semeadura direta podem ser explicados por seu maior teor na camada de 0-0,025 m (Quadro 1), bem como, provavelmente, pela mineralização desses elementos, decorrente do ataque microbiano aos resíduos culturais presentes na superfície, liberandoos regularmente ao sol o. Além disso, os sedimentos orgânicos e minerais disponíveis para o transporte pela erosão nesse tratamento eram, provavel mente,

Quadro 2. Teores de P extraível e K, Ca e Mg trocáveis no sedimento da erosão, em diferentes sistemas de preparo e cultivo do solo e ciclo cultural num Cambissolo Húmico alumínico (média da rotação e sucessão de culturas)

\begin{tabular}{|c|c|c|c|c|c|c|c|c|}
\hline Ciclo cultural & sSC & $\mathbf{A}+\mathbf{G}$ & $\mathbf{E}+\mathbf{G}$ & SDI & SSC & $\mathbf{A}+\mathbf{G}$ & $\mathbf{E}+\mathbf{G}$ & SDI \\
\hline & & & & , & & & & \\
\hline & \multicolumn{4}{|c|}{$\mathbf{P}$} & \multicolumn{4}{|c|}{$\mathbf{K}$} \\
\hline 2 & 5,1 & 2,1 & 4,7 & 12,6 & 781 & 1.177 & 1.908 & 1.994 \\
\hline 3 & 20,0 & 51,1 & 70,0 & 78,2 & 127 & 560 & 573 & 957 \\
\hline 4 & 19,8 & 76,0 & 206,5 & 258,1 & 147 & 354 & 486 & 571 \\
\hline 5 & 23,6 & 44,3 & 58,3 & 66,5 & 90 & 310 & 392 & 308 \\
\hline 6 & 16,9 & 35,9 & 19,9 & 24,5 & 141 & 165 & 368 & 278 \\
\hline 7 & 16,2 & 29,8 & 54,0 & 50,4 & 308 & 373 & 562 & 447 \\
\hline 8 & 27,0 & 50,0 & 60,5 & 59,5 & 150 & 240 & 275 & 300 \\
\hline 9 & 14,0 & 34,5 & 31,5 & 76,0 & 72 & 239 & 324 & 310 \\
\hline 10 & 32,5 & 80,3 & 122,5 & 272,9 & 134 & 200 & 283 & 447 \\
\hline 11 & 11,1 & 40,0 & 73,2 & 136,6 & 79 & 173 & 290 & 453 \\
\hline 12 & 9,0 & 26,7 & 56,0 & 120,0 & 111 & 392 & 516 & 556 \\
\hline Média & 17,7 & 42,8 & 68,8 & 105,0 & 194 & 380 & 543 & 602 \\
\hline \multirow[t]{2}{*}{ C.V. (\%) } & 43,1 & 49,0 & 76,3 & 79,1 & 100,3 & 72,4 & 81,8 & 79,3 \\
\hline & \multicolumn{4}{|c|}{$\mathrm{Ca}$} & \multicolumn{4}{|c|}{$\mathbf{M g}$} \\
\hline 2 & 3,0 & 3,5 & 4,1 & 4,8 & 1,8 & 2,0 & 2,0 & 2,1 \\
\hline 3 & 8,9 & 9,2 & 7,9 & 7,9 & 7,5 & 7,7 & 8,7 & 8,7 \\
\hline 4 & 2,4 & 3,9 & 4,5 & 4,7 & 2,0 & 3,2 & 3,8 & 3,9 \\
\hline 8 & 2 & 2,4 & 2,6 & 2,35 & 1,2 & 1,3 & 1,5 & 1,2 \\
\hline 10 & 3,3 & 3,6 & 4,2 & 4,5 & 2,4 & 2,3 & 2,4 & 2,8 \\
\hline 11 & 2,8 & 3,7 & 4,7 & 5,1 & 1,8 & 2,5 & 2,5 & 3,0 \\
\hline 12 & 3,1 & 4,5 & 4,5 & 4,7 & 2,1 & 2,4 & 2,6 & 2,5 \\
\hline Média & 3,6 & 4,4 & 4,6 & 4,9 & 2,7 & 3,1 & 3,4 & 3,5 \\
\hline C.V. (\%) & 60,0 & 46,6 & 32,0 & 30,9 & 74,3 & 64,4 & 67,8 & 65,8 \\
\hline
\end{tabular}

2: 09/06/93 a 17/11/93; 3: 18/11/93 a 12/07/94; 4: 13/07/94 a 18/11/94; 8: 01/05/96 a 15/11/96; 10: 01/05/97 a 15/11/97; 11: 16/11/97 a 30/ 04/98; 12: 01/05/98 a 30/10/98.

Sistemas de preparo do solo: SSC - solo sem cultura com aração + duas gradagens; A + G - aração + duas gradagens; E + G escarificação + gradagem; SDI - semeadura direta. C.V.: coeficiente de variação. 
col oidais, com alta afinidade por fósforo e potássio, razão por que devem ter contribuído para a alta concentração desses el ementos no sedimento oriundo da semeadura direta.

Os teores de fósforo e potássio na suspensão da erosão, foram, em geral, maiores nos sistemas de preparo conservacionistas, na média dos ciclos culturais estudados (Quadro 3), tendo sido muito baixo no caso do fósforo. N o caso do cál cio emagnésio, eles foram muito baixos e praticamente iguais em todos os tratamentos estudados. Em média, o potássio apresentou um teor cerca de três vezes maior na semeadura direta do que na aração + gradagem, explicada, provavelmente, pelo maior teor no solo (Quadro 1) e no sedimento (Quadro 2) e, ainda, pela sua maior solubilidade em água em relação aos demais nutrientes.

Na semeadura direta, oteor defósforoepotássiono sedimento da erosão (Quadro 2) foi, respectivamente,
152 e 32 vezes mai or do quena suspensão(Quadro 3), na média dos períodos estudados, concordando com dados de Burwell et al. (1975) e Bertol (1994). I sto indica que o fósforo pode tornar-se um sério problema de contaminação ambiental por eutrofização das águas, além de contribuir para elevar o custo de produção, principalmente se as perdas de sol o nesse sistema forem el evadas.

As perdas totais de nutrientes no sedimento da erosão foram, em geral, baixas (Quadro 4). Isto é explicado principal mente pelas baixas perdas desolo observadas (Schick et al., 2000), com exceção do tratamento aração + duas gradagens + solo sem cultura, no qual a perda de solo foi alta e a concentração dos nutrientes foi baixa. Contribuiu para isto o fato de ter-se analisado apenas o fósforo extraível e potássio, cálcio e magnésio trocáveis, e não os teores totais dos referidos elementos no sedimento. Baixas perdas de nutrientes também foram verificadas por Schwarz (1997).

Quadro 3. Teores de P, K, Ca e Mg solúveis na suspensão da erosão, em diferentes sistemas de preparo e cultivo do solo e ciclo cultural num Cambissolo Húmico alumínico (média da rotação e sucessão de culturas)

\begin{tabular}{|c|c|c|c|c|c|c|c|c|}
\hline Ciclo cultural & SSC & $\mathbf{A}+\mathbf{G}$ & $\mathbf{E}+\mathbf{G}$ & SDI & SSC & $\mathbf{A}+\mathbf{G}$ & $\mathbf{E}+\mathbf{G}$ & SDI \\
\hline & \multicolumn{4}{|c|}{$\mathbf{P}$} & \multicolumn{4}{|c|}{$\mathbf{K}$} \\
\hline 2 & 0,80 & 2,25 & 1,75 & 2,20 & 14,60 & 26,00 & 21,60 & 50,80 \\
\hline 3 & 1,00 & 2,10 & 3,55 & 1,75 & 2,90 & 8,20 & 8,90 & 17,20 \\
\hline 4 & 0,26 & 0,14 & 1,59 & 0,33 & 10,40 & 23,50 & 31,00 & 30,00 \\
\hline 5 & 0,03 & 0,18 & 0,76 & 0,14 & 4,50 & 6,80 & 14,95 & 10,80 \\
\hline 6 & 0,04 & 0,05 & 0,04 & 0,11 & 20,30 & 30,00 & 61,00 & 30,50 \\
\hline 7 & 0,05 & 0,05 & 0,38 & 0,29 & 2,50 & 6,85 & 10,15 & 15,60 \\
\hline 8 & 0,01 & 0,07 & 0,10 & 0,13 & 3,10 & 6,90 & 8,95 & 13,65 \\
\hline 9 & 0,01 & 0,06 & 0,13 & 0,12 & 1,60 & 3,55 & 4,95 & 6,35 \\
\hline 10 & 0,11 & 0,41 & 0,84 & 1,08 & 2,30 & 3,50 & 4,50 & 7,95 \\
\hline 11 & 0,53 & 0,39 & 0,36 & 0,62 & 2,40 & 4,00 & 7,20 & 14,90 \\
\hline 12 & 0,32 & 0,40 & 0,60 & 0,86 & 2,40 & 3,75 & 5,85 & 11,43 \\
\hline Média & 0,29 & 0,55 & 0,92 & 0,69 & 6,09 & 11,19 & 16,28 & 19,02 \\
\hline \multirow[t]{2}{*}{ C.V. (\%) } & 114,99 & 140,06 & 108,24 & 98,71 & 97,66 & 85,86 & 98,90 & 66,97 \\
\hline & \multicolumn{4}{|c|}{$\mathrm{Ca}$} & \multicolumn{4}{|c|}{ Mg } \\
\hline 2 & 0,22 & 0,17 & 0,20 & 0,20 & 0,14 & 0,12 & 0,12 & 0,16 \\
\hline 3 & 0,12 & 0,10 & 0,10 & 0,09 & 0,10 & 0,09 & 0,08 & 0,07 \\
\hline 8 & 0,01 & 0,01 & 0,01 & 0,01 & 0,01 & 0,01 & 0,01 & 0,01 \\
\hline 10 & 0,05 & 0,04 & 0,04 & 0,03 & 0,03 & 0,03 & 0,03 & 0,02 \\
\hline 11 & 0,02 & 0,03 & 0,03 & 0,04 & 0,02 & 0,03 & 0,03 & 0,05 \\
\hline 12 & 0,04 & 0,04 & 0,03 & 0,04 & 0,02 & 0,03 & 0,03 & 0,04 \\
\hline Média & 0,08 & 0,07 & 0,07 & 0,07 & 0,05 & 0,05 & 0,05 & 0,06 \\
\hline C.V. (\%) & 95,45 & 83,68 & 95,37 & 93,10 & 91,64 & 76,13 & 75,72 & 84,80 \\
\hline
\end{tabular}

2: 09/06/93 a 17/11/93; 3: 18/11/93 a 12/07/94; 8: 01/05/96 a 15/11/96; 10: 01/05/97 a 15/11/97; 11: 16/11/97 a 30/04/98; 12: 01/05/98 a 30/10/98.

Sistemas de preparo do solo: SSC - solo sem cultura com aração + duas gradagens; A + G - aração + duas gradagens; E + G escarificação + gradagem; SDI - semeadura direta. C.V.: coeficiente de variação. 
A perda total de fósforo no sedimento da erosão foi, em geral, baixa, pelo fato de estar presente em baixas concentrações no solo e ser adsorvido aos colóides, concordando com dados obtidos por Castro et al. (1986) eDedecek et al. (1986). Apesar dea aração + duas gradagens + solo sem cultura apresentar os menores teores desse elemento (Quadro 1), a sua perda total por erosão foi maior do que nos demais tratamentos, explicada pela maior perda de solo ocorrida nesse tratamento (Schick et al., 2000).

Em geral, a perda total de potássio no sedimento da erosão foi maior do quea defósforo, o quetambém foi verificado por Castro et al. (1986), Dedecek et al . (1986) e Seganfredo et al. (1997). I sto ocorreu pela sua maior solubilidade em relação ao fósforo, o que facilitou o transporte pela água e, principalmente, por seu maior teor no solo (Quadro 1).

De modo geral, cálcio e magnésio são perdidos em grandes quantidades no sedimento da erosão (Castroet al., 1986; Dedecek et al., 1986; Bertol, 1994), em razão docal cárioadicionadoaosolo. Especialmente o cálcio éadsorvido aos col óides do sol o, o que facilita o seu transporte no sedimento. Embora o cál cio e o magnésio sejam adicionados ao solo em quantidades relativamente grandes, por ocasião da calagem, a retirada desses elementos pelo processo erosivo tende a acelerar a reacidificação do solo.

As perdas totais de nutrientes na suspensão da erosão foram, em geral, altas (Quadro 5), contrariando dados obtidos por Burwell et al. (1975) e Laflen \& Tabatabai (1984), os quais observaram que a perda da maior parte destes elementos está associada ao sedimento da erosão. Isto é devido ao fato de não ter sido feita a separação do material coloidal em suspensão na enxurrada por meio de filtragem, como o fizeram os autores supracitados, e, além disso, terem sido as perdas de água relativamente altas (Schick et al., 2000). Assim, apesar de ser o teor dos nutrientes relativamente baixo na suspensão da erosão (Quadro 3), as

Quadro 4. Perdas totais de $P$ extraível e $K$, Ca e Mg trocáveis no sedimento da erosão, em diferentes sistemas de preparo e cultivo do solo e ciclo cultural num Cambissolo Húmico alumínico (média da rotação e sucessão de culturas)

\begin{tabular}{|c|c|c|c|c|c|c|c|c|}
\hline Ciclo cultural & ssC & $\mathbf{A}+\mathbf{G}$ & $\mathbf{E}+\mathbf{G}$ & SDI & SSC & $\mathbf{A}+\mathbf{G}$ & $\mathbf{E}+\mathbf{G}$ & SDI \\
\hline & \multicolumn{4}{|c|}{$\mathbf{P}$} & \multicolumn{4}{|c|}{$\mathbf{K}$} \\
\hline 2 & 0,29 & 0,01 & 0,01 & 0,01 & 44,20 & 3,86 & 3,34 & 1,39 \\
\hline 3 & 0,75 & 0,16 & 0,03 & 0,01 & 4,75 & 1,58 & 0,19 & 0,10 \\
\hline 4 & 0,06 & 0,01 & 0,03 & 0,02 & 0,45 & 0,07 & 0,08 & 0,05 \\
\hline 5 & 0,07 & 0,02 & 0,04 & 0,01 & 0,25 & 0,12 & 0,27 & 0,07 \\
\hline 6 & 0,04 & 0,01 & 0,01 & 0,00 & 0,29 & 0,03 & 0,13 & 0,02 \\
\hline 7 & 1,36 & 0,06 & 0,09 & 0,02 & 25,80 & 0,70 & 0,92 & 0,19 \\
\hline 8 & 0,15 & 0,13 & 0,14 & 0,02 & 0,81 & 0,59 & 0,62 & 0,12 \\
\hline 9 & 1,03 & 0,03 & 0,02 & 0,02 & 5,29 & 0,19 & 0,19 & 0,08 \\
\hline 10 & 0,47 & 0,13 & 0,07 & 0,14 & 1,93 & 0,35 & 0,15 & 0,23 \\
\hline 11 & 1,24 & 0,34 & 0,66 & 0,56 & 8,83 & 1,53 & 2,46 & 1,86 \\
\hline 12 & 0,32 & 0,17 & 0,29 & 0,58 & 2,93 & 1,74 & 1,15 & 1,16 \\
\hline Total & 5,76 & 1,07 & 1,37 & 1,41 & 95,55 & 10,76 & 9,50 & 5,27 \\
\hline M édia & 0,53 & 0,10 & 0,13 & 0,13 & 8,68 & 0,98 & 0,86 & 0,48 \\
\hline \multirow[t]{2}{*}{ C.V. (\%) } & 89,14 & 100,45 & 147,21 & 168,02 & 152,58 & 112,23 & 119,66 & 131,11 \\
\hline & \multicolumn{4}{|c|}{$\mathrm{Ca}$} & \multicolumn{4}{|c|}{ Mg } \\
\hline 2 & 33,96 & 2,37 & 1,43 & 0,62 & 12,23 & 0,84 & 0,42 & 0,17 \\
\hline 3 & 66,83 & 5,85 & 0,67 & 0,23 & 33,44 & 2,93 & 0,41 & 0,14 \\
\hline 4 & 1,47 & 0,15 & 0,14 & 0,08 & 0,73 & 0,07 & 0,07 & 0,04 \\
\hline 8 & 2,16 & 1,23 & 1,17 & 0,19 & 0,75 & 0,37 & 0,41 & 0,06 \\
\hline 10 & 9,63 & 1,22 & 0,44 & 0,46 & 4,06 & 0,49 & 0,16 & 0,18 \\
\hline 11 & 62,62 & 6,96 & 8,13 & 4,20 & 24,60 & 2,97 & 2,57 & 1,48 \\
\hline 12 & 16,18 & 3,27 & 1,85 & 1,83 & 6,71 & 1,26 & 0,62 & 0,67 \\
\hline Total & 192,86 & 21,05 & 13,83 & 7,62 & 82,51 & 8,94 & 4,65 & 2,73 \\
\hline Média & 27,55 & 3,01 & 1,98 & 1,09 & 11,79 & 1,28 & 0,67 & 0,39 \\
\hline C.V. (\%) & 92,94 & 78,19 & 130,13 & 127,30 & 99,48 & 87,33 & 119,50 & 124,14 \\
\hline
\end{tabular}

2: 09/06/93 a 17/11/93; 3: 18/11/93 a 12/07/94; 4: 13/07/94 a 18/11/94; 8: 01/05/96 a 15/11/9610: 01/05/97 a 15/11/97; 11: 16/11/97 a 30/ 04/98; 12: 01/05/98 a 30/10/98.

Sistemas de preparo do solo: SSC - solo sem cultura com aração + duas gradagens; A + G - aração + duas gradagens; E + G escarificação + gradagem; SDI - semeadura direta. C.V.: coeficiente de variação. 
quantidades totais de nutrientes perdidas (Quadro 5) foram maiores do que aquelas perdidas no sedimento (Quadro 4). A quantidade total de fósforo e potássio perdida na suspensão da erosão foi, respectivamente, 13 e 3 vezes superior à do sedimento, na média dos ciclos culturais e tipos de preparo estudados. Diante disso, considera-se necessário adotar práticas conservacionistas voltadas à redução das perdas de água, além dos sedimentos.

As perdas de nutrientes, embora tenham sido relativamente baixas no presente estudo, podem representar expressiva parcela do total necessário à maioria das culturas. Bataglia et al. (1976) observaram que a soja extraiu 24 e 118 kg ha-1 de fósforo e potássio, respectivamente, para atender à parte aérea eà produção desementes duranteo ciclo. Considerando a perda total ocorrida no período experimental, a semeadura direta perdeu cerca de 38 e $108 \%$ do fósforo e do potássio, respectivamente, necessários para a cultura de soja durante um ciclo (Quadro 6).

Estes dados mostram que, em sistemas depreparo e manejo onde as perdas de sol o e água são altas, a erosão é um fator importante no empobrecimento do solo, com possíveis reflexos no aumento do custo de produção das culturas e na poluição de mananciais por eutr ofização das águas.

Os teores dos nutrientes e do carbono orgânico no sedimento da erosão apresentaram correlação positiva com a composição química da camada de 0$0,025 \mathrm{~m}$ do solo de onde se originou o sedimento (Figuras 1 e 2). Dentre os nutrientes, o fósforo apresentou a maior taxa de enriquecimento, com valor de 1,0849, seguido do potássio, cálcio e magnésio, com valores de 0,9374, 0,8086 e 0,7567, respectivamente (Figura 1 ). O fósforo apresentou taxa de enriquecimento cerca de $8 \%$ maior no sedimento erodido do que no solo de onde se originou o sedimento, sendo, por isso, o nutriente mais

Quadro 5. Perdas totais de $P, K$, Ca e Mg solúveis na suspensão da erosão, em diferentes sistemas de preparo e cultivo do solo e ciclo cultural num Cambissolo Húmico alumínico (média da rotação e sucessão de culturas)

\begin{tabular}{|c|c|c|c|c|c|c|c|c|}
\hline Ciclo cultural & ssC & $\mathbf{A}+\mathbf{G}$ & $\mathbf{E}+\mathbf{G}$ & SDI & SSC & $\mathbf{A}+\mathbf{G}$ & $\mathbf{E}+\mathbf{G}$ & SDI \\
\hline & \multicolumn{4}{|c|}{$\mathbf{P}$} & \multicolumn{4}{|c|}{$\mathbf{K}$} \\
\hline $\begin{array}{r}2 \\
3 \\
4 \\
5 \\
6 \\
7 \\
8 \\
9 \\
10 \\
11 \\
12\end{array}$ & $\begin{array}{l}1,41 \\
2,32 \\
0,15 \\
0,00 \\
0,02 \\
0,11 \\
0,01 \\
0,02 \\
0,38 \\
1,73 \\
1,13\end{array}$ & $\begin{array}{l}2,77 \\
2,93 \\
0,01 \\
0,01 \\
0,00 \\
0,04 \\
0,03 \\
0,08 \\
1,50 \\
1,46 \\
0,97\end{array}$ & $\begin{array}{l}1,80 \\
3,03 \\
0,25 \\
0,04 \\
0,01 \\
0,19 \\
0,05 \\
0,14 \\
0,92 \\
0,53 \\
0,67\end{array}$ & $\begin{array}{l}2,69 \\
0,52 \\
0,04 \\
0,00 \\
0,00 \\
0,03 \\
0,03 \\
0,10 \\
1,54 \\
0,73 \\
1,46\end{array}$ & $\begin{array}{r}25,80 \\
6,73 \\
6,07 \\
0,72 \\
8,04 \\
5,74 \\
3,04 \\
3,48 \\
7,91 \\
7,84 \\
8,27\end{array}$ & $\begin{array}{r}30,44 \\
11,70 \\
2,82 \\
0,23 \\
1,91 \\
4,76 \\
3,63 \\
5,28 \\
13,32 \\
12,36 \\
8,74\end{array}$ & $\begin{array}{r}21,86 \\
7,88 \\
5,07 \\
0,84 \\
9,61 \\
5,25 \\
4,79 \\
5,54 \\
5,16 \\
11,44 \\
6,72\end{array}$ & $\begin{array}{r}55,40 \\
6,54 \\
2,09 \\
0,25 \\
0,69 \\
1,33 \\
2,33 \\
5,47 \\
11,32 \\
17,85 \\
18,09\end{array}$ \\
\hline Total & 7,28 & 9,80 & 7,63 & 7,14 & 83,64 & 95,19 & 84,16 & 121,36 \\
\hline Média & 0,66 & 0,89 & 0,69 & 0,65 & 7,60 & 8,65 & 7,65 & 11,03 \\
\hline \multirow[t]{2}{*}{ C.V. (\%) } & 120,55 & 121,36 & 129,15 & 130,74 & 81,62 & 93,60 & 68,11 & 139,06 \\
\hline & \multicolumn{4}{|c|}{$\mathrm{Ca}$} & \multicolumn{4}{|c|}{ Mg } \\
\hline $\begin{array}{r}2 \\
3 \\
8 \\
10 \\
11 \\
12\end{array}$ & $\begin{array}{r}77,75 \\
53,82 \\
2,55 \\
35,43 \\
13,72 \\
25,52\end{array}$ & $\begin{array}{r}32,59 \\
29,15 \\
1,03 \\
34,01 \\
20,60 \\
18,56\end{array}$ & $\begin{array}{r}38,62 \\
16,42 \\
1,48 \\
11,26 \\
9,64 \\
8,70\end{array}$ & $\begin{array}{r}40,03 \\
5,70 \\
0,31 \\
9,52 \\
8,53 \\
12,35\end{array}$ & $\begin{array}{r}30,04 \\
26,91 \\
0,98 \\
11,70 \\
6,53 \\
9,50\end{array}$ & $\begin{array}{r}15,47 \\
14,50 \\
0,44 \\
13,28 \\
12,01 \\
8,72\end{array}$ & $\begin{array}{r}14,49 \\
8,19 \\
0,64 \\
5,15 \\
5,48 \\
4,31\end{array}$ & $\begin{array}{r}19,91 \\
2,86 \\
0,14 \\
3,70 \\
6,76 \\
7,30\end{array}$ \\
\hline Total & 208,79 & 135,94 & 86,12 & 76,44 & 85,66 & 64,42 & 38,26 & 40,67 \\
\hline Média & 34,80 & 22,66 & 14,35 & 12,74 & 14,28 & 10,74 & 6,38 & 6,78 \\
\hline C.V. (\%) & 72,10 & 49,62 & 81,58 & 100,16 & 74,26 & 47,30 & 66,72 & 93,62 \\
\hline
\end{tabular}

2: 09/06/93 a 17/11/93; 3: 18/11/93 a 12/07/94; 8: 01/05/96 a 15/11/96; 10: 01/05/97 a 15/11/97; 11: 16/11/97 a 30/04/98; 12: 01/05/98 a 30/10/98.

Sistemas de preparo do solo: SSC - solo sem cultura com aração + duas gradagens; A + G - aração + duas gradagens; E + G escarificação + gradagem; SDI - semeadura direta. C.V.: coeficiente de variação. 
problemático em termos de contaminação ambiental, pelo efeito de eutrofização das águas. No caso do potássio, cálcio e magnésio, os teores no sedimento oriundo da erosão foram menores do que no solo original, indicando serem menos nocivos do que o fósforo quantoà contaminação ambiental. A taxa de enriquecimento do carbono orgânico foi maior do que a dos nutrientes, com valor de 1,2386 (Figura 2), denotando-se que esse el emento é mais problemático do que os nutrientes quanto à contaminação das águas, já que sua concentração no sedimento erodido foi cerca de $24 \%$ maior do que no solo de onde se originou o sedimento. Assim, é possível predizer o teor desses nutrientes e do carbono orgânico no sedimento da erosão por meio das equações ajustadas para cada elemento (Figuras 1 e 2), considerando o grau de confiabilidade conferido pel os respectivos coeficientes de correlação, a partir do conhecimento do teor desses elementos na camada de $0-0,025 \mathrm{~cm}$ do solo.
As taxas de enriquecimento dos nutrientes e do carbono orgânico estudados (Quadro 7) concordam, em geral, com aqueles obtidos por Dedecek et al. (1986) e Schwarz (1997), discordando, no entanto, daqueles obtidos por Eltz (1977), o qual observou mai ores teores de nutrientes no material erodido do que no sol o original. I sto pode ser atribuído ao fato de que se utilizaram os teores dos elementos na camada de 0-0,025 $\mathrm{m}$ do solo, a qual normalmente apresenta maiores concentrações desses el ementos, ao passo que EItz (1977) utilizou a concentração média na camada de 0-0,2 m do solo.

O fósforo e o carbono orgânico apresentaram as maiores taxas de enriquecimento (Quadro 7). Tal comportamento pode ser explicado, no caso do carbono, pelo fato de ser a matéria orgânica o primeiro constituinte a ser removido pela erosão, considerando sua al ta concentração na superfície do solo e, principalmente, sua baixa densidade, o que justifica a maior concentração de carbono no

Quadro 6. Perdas totais de P, K, Ca e Mg no sedimento e suspensão da erosão, em diferentes sistemas de preparo e cultivo do solo e ciclo cultural num Cambissolo Húmico alumínico (média da rotação e sucessão de culturas)

\begin{tabular}{|c|c|c|c|c|c|c|c|c|}
\hline Ciclo cultural & ssc & $\mathbf{A}+\mathbf{G}$ & $\mathbf{E}+\mathbf{G}$ & SDI & ssc & $\mathbf{A}+\mathbf{G}$ & $\mathbf{E}+\mathbf{G}$ & SDI \\
\hline & & & & $m$ & $g^{-1}$ & & & \\
\hline & \multicolumn{4}{|c|}{$\mathbf{P}$} & \multicolumn{4}{|c|}{$\mathbf{K}$} \\
\hline 2 & 1,7 & 2,8 & 1,8 & 2,7 & 70,0 & 34,3 & 25,2 & 56,8 \\
\hline 3 & 3,1 & 3,1 & 3,1 & 0,5 & 11,5 & 13,3 & 81 & 6,6 \\
\hline 4 & 0,2 & 0,0 & 0,3 & 0,1 & 6,5 & 2,9 & 5,2 & 2,1 \\
\hline 5 & 0,1 & 0,0 & 0.1 & 0.0 & 1.0 & 0,4 & 1,1 & 0,3 \\
\hline 6 & 0,1 & 0,0 & 0,0 & 0,0 & 8,3 & 1,9 & 9,7 & 0,7 \\
\hline 7 & 1,5 & 0,1 & 0,3 & 0,1 & 31,5 & 5,5 & 6,2 & 1,5 \\
\hline 8 & 0,2 & 0,2 & 0,2 & 0,1 & 3,9 & 4,2 & 5,4 & 2,5 \\
\hline 9 & 1,1 & 0,1 & 0,2 & 0,1 & 8,8 & 5,5 & 5,7 & 5,6 \\
\hline 10 & 0,9 & 1,6 & 1,0 & 1,7 & 9.8 & 13,7 & 5,3 & 11,6 \\
\hline 11 & 3,0 & 1,8 & 1,2 & $\begin{array}{l}1,1 \\
1,3\end{array}$ & 16,7 & 13,9 & 13,9 & 19,7 \\
\hline 12 & 1,5 & 1,1 & 1,0 & 2,0 & 11,2 & 10,5 & 7,9 & 19,3 \\
\hline Total & 13,1 & 10,9 & 9,0 & 8,5 & 179,3 & 106,0 & 93,7 & 126,7 \\
\hline M édia & 1,2 & 1,0 & 0,8 & 0,8 & 16,3 & 9,6 & 8,5 & 11,5 \\
\hline \multirow[t]{2}{*}{ C.V. (\%) } & 85,0 & 114,6 & 107,3 & 118,5 & 114,2 & 94,4 & 71,6 & 137,3 \\
\hline & \multicolumn{4}{|c|}{$\mathrm{Ca}$} & \multicolumn{4}{|c|}{ Mg } \\
\hline 2 & 111,7 & 35,0 & 40,1 & 40,7 & 42,3 & 16,3 & 14,9 & 20,1 \\
\hline 3 & 120,7 & 35,0 & 17,1 & 5,9 & 60,4 & 17,4 & 8,6 & 3,0 \\
\hline 4 & 1,5 & 0,2 & 0,1 & 0,1 & 0,7 & 0,1 & 0,1 & 0,0 \\
\hline 8 & $4,7^{(1)}$ & $2,3^{(1)}$ & $2,7^{(1)}$ & $0,5^{(1)}$ & $1,7^{(1)}$ & $0,8^{(1)}$ & $1,1^{(1)}$ & $0,2^{(1)}$ \\
\hline 10 & 45,1 & 35,2 & 11,7 & 10,0 & 15,8 & 13,8 & 5,3 & 3,9 \\
\hline 11 & 76,3 & 27,6 & 17,8 & 12,7 & 31,1 & 15,0 & 8,1 & 8,2 \\
\hline 12 & 41,7 & 21,8 & 10,6 & 14,2 & 16,2 & 10,0 & 4,9 & 8,0 \\
\hline Total & 401,7 & 157,0 & 99,9 & 84,1 & 168,2 & 73,3 & 43,0 & 43,4 \\
\hline Média & 57,4 & 22,4 & 14,3 & 12,0 & 24,0 & 10,5 & 6,1 & 6,2 \\
\hline C.V. (\%) & 76,8 & 63,1 & 85,3 & 106,4 & 84,4 & 64,0 & 75,5 & 103,9 \\
\hline
\end{tabular}

2: 09/06/93 a 17/11/93; 3: 18/11/93 a 12/07/94; 4: 13/07/94 a 18/11/94; 8: 01/05/96 a 15/11/96; 10: 01/05/97 a 15/11/97; 11: 16/11/97 a 30/ 04/98; 12: 01/05/98 a 30/10/98.

Sistemas de preparo do solo: SSC - solo sem cultura com aração + duas gradagens; A + G - aração + duas gradagens; E + G escarificação + gradagem; SDI - semeadura direta. C.V.: coeficiente de variação. ${ }^{(1)}$ resultado das perdas ocorridas apenas no sedimento. 


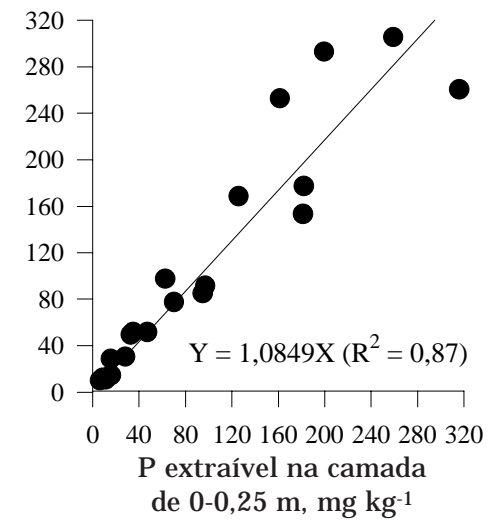

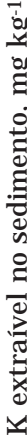

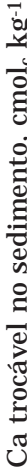

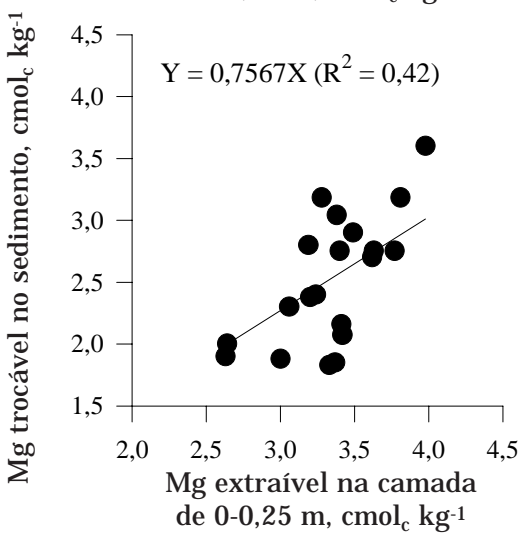

Figura 1. Relação do fósforo extraível e potássio, cálcio e magnésio trocáveis contidos na camada de 0-0,025 m de profundidade do solo e no sedimento da erosão hídrica, em três ciclos culturais num Cambissolo Húmico alumínico (média da rotação e sucessão de culturas). sedimento em relação à camada de $0-0,025 \mathrm{~m}$ do sol o. No caso do fósforo, o qual se encontra adsorvido aos colóides, este comportamento pode ser devido à textura do material transportado pela erosão, o qual provavel mente é mais rico em silte e argila do que o solo de onde ele se originou, uma vez que estas frações granulométricas são as mais facilmente transportadas e mais ricas em nutrientes adsorvidos (Freitas \& Castro, 1983).

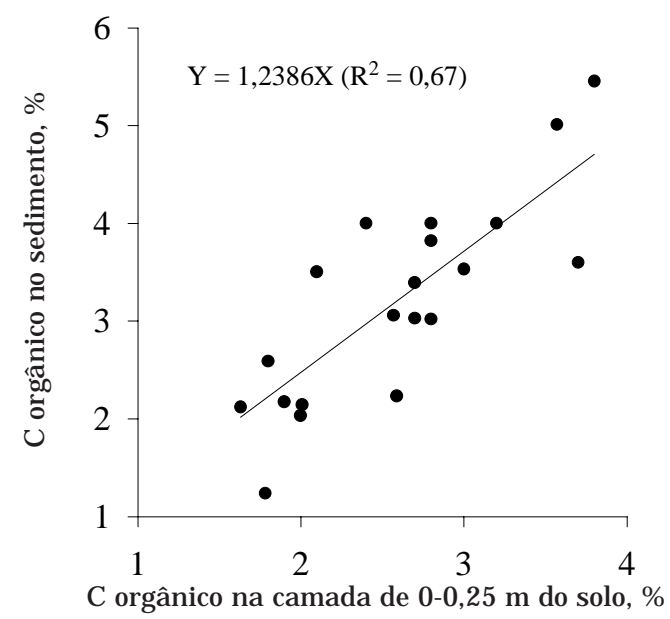

Figura 2. Relação do carbono orgânico contido na camada de $0-0,025 \mathrm{~m}$ de profundidade do solo e no sedimento da erosão hídrica, em três ciclos culturais num Cambissolo Húmico alumínico (média da rotação e sucessão de culturas).

Quadro 7. Taxas de enriquecimento de P extraível, K, Ca e Mg trocáveis e carbono orgânico, em diferentes sistemas de preparo do solo num Cambissolo Húmico alumínico, no período de 05/97 a 10/98 (média da rotação e sucessão de culturas e de três ciclos culturais)

\begin{tabular}{cccccc}
\hline Tratamento & P & K & Ca & Mg & C \\
\hline SSC & 1,7 & 1,1 & 0,7 & 0,6 & 1,1 \\
A + G & 1,7 & 1,1 & 0,8 & 0,7 & 1,7 \\
E + G & 1,3 & 0,9 & 0,9 & 0,8 & 0,9 \\
SDI & 1,2 & 1,3 & 0,8 & 0,7 & 1,5
\end{tabular}

Sistemas de preparo do solo: SSC - solo sem cultura com aração + duas gradagens; A + G - aração + duas gradagens; $E$ + G - escarificação + gradagem; SDI - semeadura direta.

\section{CONCLUSÕES}

1. Os teores de fósforo extraível e potássio, cálcio e magnésio trocáveis no sedimento da erosão foram 
maiores nos preparos conservacionistas de solo do que nos preparos convencionais; na suspensão, por outro lado, apenas o fósforo extraível e o potássio trocável apresentaram esse comportamento; a concentração de todos os elementos foi maior no sedimento do que na suspensão.

2. As perdas totais de fósforo extraível e potássio, cál cio e magnésio trocáveis no sedimento da erosão foram relativamente baixas, sendo maiores nos preparos convencionais, nos quais as perdas de solo foram mais altas; na suspensão, por outro lado, as perdas totais dos referidos nutrientes foram altas e relativamente semel hantes nos diversos sistemas de preparo do solo.

3. As perdas de carbono orgânico foram altas em todos os sistemas de preparo do solo, especialmente naqueles cujas perdas de sol o foram el evadas.

4. Os teores de fósforo extraível e potássio, cálcio emagnésio trocáveis ecarbono orgâni co no sedimento da erosão correlacionaram-se linear e positivamente com a composi ção química do sol o do qual se originou na camada de 0-0,025 m de profundidade; a taxa de enriquecimento dos referidos el ementos mostrou-se próxima a um.

\section{LITERATURA CITADA}

BATAGLIA, O.C.; MASCARENHAS, H.A.A.; TEIXEIRA, J .P.F. \& TISSELLI FILHO, O. Acúmulo de matéria seca e nutrientes em soja cultivar Santa Rosa. Bragantia, 35:237248, 1976.

BERTOL, I. Perdas de nutrientes por erosão hídrica em diferentes sistemas de manejo de solo sob rotação de culturas. Univ. \& Des., 2:174-184, 1994.

BERTOL, I. \& MIQUELLUTI, D.J. Perdas de solo, água e nutrientes reduzidas pela cultura do milho. Pesq. Agropec. Bras., 28:1205-1213, 1993.

BURWELL, R.E.; TIMMONS, D.R. \& HOLT, R.F. Nutrient transport in surface runoff as influenced by soil cover and seasonal periods. Soil Sci. Soc. Am. Proc., 39:523-528, 1975.

CASTRO, O.M.; LOMBARDI NETO, F.; QUAGGIO,J .A.; MARIA, I.C.; VIEIRA, S.R. \& DECHEN, S.C.F. Perdas por erosão de nutrientes vegetais na sucessão soja/trigo em diferentes sistemas de manejo. R. Bras. Ci. Solo, 10:293-297, 1986.
COGO, N.P. U ma contribuiçãoà metodologia de estudo das perdas por erosão em condições de chuva natural. I. Sugestões gerais, medição do volume, amostragem e quantificação de solo eágua da enxurrada (1a aproximação). In: ENCONTRO NACIONAL DE PESQUISA SOBRE CONSERVAÇÃO DO SOLO, 2., Passo Fundo, 1978. Anais. PassoFundo, Empresa Brasileira de Pesquisa Agropecuária, 1978. p.75-98.

DEDECEK, R.A.; RESK, D.V.S. \& FREITAS J r. E. Perdas desolo, água enutrientes por erosão em $L$ atossolo Vermel ho-Escuro dos cerrados em diferentes cultivos sob chuva natural. R. Bras. Ci. Solo, 10:265-272, 1986.

ELTZ, F.L.F. Perdas por erosão sob precipitação natural em diferentes manejos de sol o e coberturas vegetais. I. Solo da unidade de apeamento São J erônimo - Primeira Etapa Experimental. Porto Alegre, Universidade Federal do Rio Grande do Sul, 1977. 97p. (Tese de Mestrado)

FREITAS, P.L. \& CASTRO, A.F. Estimativas das perdas de solo e nutrientes por erosão no Estado do Paraná. B. Inf. SBCS, 8:43-52, 1983.

LAFLEN, J .M. \& TABATABAI, M.A. Nitrogen and phosphorus losses from corn-soybeans rotation as affected by tillage practices. Trans. Am. Soc. Agric. Eng., 27:58-63, 1984.

McDOWELL, L.L. \& McGREGOR, K.C. Plant nutrient losses in runoff from conservation tillage corn. Soil Till. Res., 4:7991, 1984.

SCHICK, J . E rosão hídrica em cambissolo húmico álico submetido a diferentes sistemas de manejo e cultivo do solo. Lages, Centro de Ciências Agroveterinárias- Universidade para o Desenvolvimento do Estado de Santa Catarina, 1999. 114p. (Tese de Mestrado)

SCHICK, J .; BERTOL, I.; BATISTELA, O. \& BALBINOT J ÚNIOR, A.A. Erosão hídrica em cambissolo húmico alumínico submetido a diferentes sistemas de preparo e cultivo do solo: I. perdas de solo e água. R. Bras. Ci. Solo, 24:427-436, 2000.

SCHWARZ, R.A. Perdas por erosão hídrica em diferentes classes de declividade, sistemas de preparo e níveis de fertilidade do solo na região das missões - RS. Porto Alegre, Universidade Federal do Rio Grande do Sul, 1997. 130p. (Tese de Mestrado)

SEGANFREDO, M.L.; ELTZ, F.LF. \& BRUM, A.C.R. Perdas de solo, água e nutrientes por erosão em sistemas de culturas em plantio direto. R. Bras. Ci. Solo, 21:287-291, 1997.

TEDESCO, M.J .; GIANELLO, C.; BISSANI, C.A.; BOHNEN, H. \& VOLKWEISS, S.J. Análise de solos, plantas e outros materiais. 2.ed. Porto Alegre, Universidade Federal do Rio Grande do Sul, 1995. 174p. 
J. SCHICK et al. 